\title{
The relationship between postmenopausal women's body image and the severity of menopausal symptoms
}

Soheila Nazarpour ${ }^{1}$, Masoumeh Simbar ${ }^{2,3^{*}}$ (D), Hamid Alavi Majd ${ }^{4}$, Zahra Jafari Torkamani ${ }^{3}$, Khadijeh Dodel Andarvar ${ }^{3}$ and Fatemeh Rahnemaei ${ }^{3}$

\begin{abstract}
Background: Body image is the main element of an individual's personality that may be influenced by many factors during menopause. We aimed to assess the relationship between postmenopausal women's body image with the severity of menopausal symptoms.

Methods: This was a cross-sectional study on 300 postmenopausal women, aged 45 to 65 years old, in Tehran, Iran. We recruited the samples using the multi-stage sampling method. Tools for data collection were: 1) the Menopausal Rating Scale (MRS), 2) the Fisher's Body Image questionnaire and 3) a socio-demographic questionnaire. We analyzed data using the independent samples $t$-test, Pearson correlation coefficient, Spearman's correlation coefficient, and multiple linear regression tests.

Results: Three hundred women aged $55.11 \pm 3.99$ years old, participated in the study. Mean scores for body image and MRS were $163.07 \pm 21.17$ (Range: 46-230) and 16.45 \pm 8.38 (Range: 0-44), respectively. About 50\% of women had severe symptoms of menopause (MRS score $\geq 17$ ). There was a negative correlation between the total score and the score of all dimensions of body image with the total score and all dimensions of MRS $(P<0.001)$. There were also significant relationships between women's body image with: their education $(P<0.001, r=0.20)$ the spouse's education $(P<0.001, r=0.26)$, adequacy of monthly household income $(P<0.001, r=0.32)$, marital status $(P=0.36)$, their occupation $(P=0.007)$ and housing status $(P=0.012)$. There was also a significant negative correlation between women's lower body organs image with the number of children $(P=0.017, r=-0.14)$. According to the multiple linear regressions model, severity of menopausal symptoms (Beta $=-0.45, P<0.001$ ) and adequacy of monthly household income (Beta $=0.15, P=0.005$ ) are the significant related factors with postmenopausal women's body image.
\end{abstract}

\footnotetext{
* Correspondence: msimbar@gmail.com

${ }^{2}$ Midwifery and Reproductive Health Research Center, Shahid Beheshti University of Medical Sciences, Tehran, Iran

${ }^{3}$ Department of Midwifery and Reproductive Health, School of Nursing and Midwifery, Shahid Beheshti University of Medical Sciences, Vali-Asr Avenue, Cross of Vali-Asr and Neiaiesh Highway, Opposite to Rajaee Heart Hospital, Tehran 1996835119, Iran

Full list of author information is available at the end of the article
}

(c) The Author(s). 2021 Open Access This article is licensed under a Creative Commons Attribution 4.0 International License, which permits use, sharing, adaptation, distribution and reproduction in any medium or format, as long as you give appropriate credit to the original author(s) and the source, provide a link to the Creative Commons licence, and indicate if changes were made. The images or other third party material in this article are included in the article's Creative Commons licence, unless indicated otherwise in a credit line to the material. If material is not included in the article's Creative Commons licence and your intended use is not permitted by statutory regulation or exceeds the permitted use, you will need to obtain permission directly from the copyright holder. To view a copy of this licence, visit http://creativecommons.org/licenses/by/4.0/. The Creative Commons Public Domain Dedication waiver (http://creativecommons.org/publicdomain/zero/1.0/) applies to the data made available in this article, unless otherwise stated in a credit line to the data. 
Conclusions: Body image is correlated with menopausal symptoms of women during menopause. Therefore, it seems that interventions aimed at relieving the annoying symptoms of menopause can help to improve their body image. Also, body image could be influenced by some socio-demographic factors which should be considered in menopause health promotion programs.

Keywords: Menopause, Body image, Menopausal symptoms, Socio-demographic factors

\section{Background}

Body image is a multidimensional, subjective and dynamic concept that encompasses a person's perceptions, thoughts, and feelings about their own body [1]. It is one of the main elements of an individuals' personality $[2,3]$. Cash and Pruzinsky defined body image as perceptions, thoughts, and feelings associated with the body and bodily experience [4]. Positive body image is also different from negative body image and it is multifaceted (including body appreciation, body acceptance/love), holistic, stable and malleable, protective, linked to self-perceived body acceptance by others; and shaped by social identities [5]. Body image is a person's perception of their physical self and the thoughts and feelings, positive, negative, or both, which result from that perception [6].

Several factors are shown to influence body image. These factors are dependent on the cultural and economic condition of every community [7, 8]. Several studies showed a relationship between body image with age $[8,9]$, gender $[9,10]$, marital status [9], educational level $[9,11]$, anxiety and depression $[7,12]$, social phobia [13], smoking and/or alcohol use [14], interpersonal sensitivity [15], obsessed behaviors [15], nutritional deficiencies [7], body mass index [10, 16, 17], low level of physical exercises [18], sexual orientation [19] sexual dysfunction and dyspareunia among women [20].

A study on 75,256 postmenopausal women showed a prevalence of $83 \%$ of body image dissatisfaction [16]. Postmenopausal period is a period of life that may influence the body image of women. Body changes with the increasing age of women may influence their body image [21] and may lead to a negative body image [22]. Majority of menopausal women experience symptoms of menopausal syndrome such as flushing, atrophic vaginitis, sexual dysfunction, insomnia, fatigue, musculoskeletal problems, cardiovascular symptoms, breast atrophy, change in shape, wrinkles in the skin, and the signs of elderly that may affect their body image [23-25]. Abbas et al. (2020) showed an association between health problems and psychological problems such as stress and anxiety [26]. It seems menopausal physical symptoms may lead to psychological problems such as depression and anxiety, and these problems could influence on body image of menopausal women [12]. While inappropriate perception and negative body image may lead to psychosomatic problems in postmenopausal women [27], positive body image improves self-confidence and satisfactory sexual life of postmenopausal women [28].

Respecting the possible effects of some postmenopausal complications on women's body image and so decreasing their quality of life, we aimed to assess the relationship between postmenopausal women's body image with the severity of menopausal symptoms.

\section{Methods \\ Study design}

This was a cross-sectional study. Three hundred women with an average age of $55.11 \pm 3.99$ years, with minimum to maximum age 45 to 65 years participated in the study. They were selected from attendees to health care centers of Tehran, Iran. These centers provide health services on an outpatient basis and are covered by the country's medical universities and the Ministry of health. The study was conducted from March to July 2020. The participants were non-surgical or non-premature menopause women. They have no history of physical or psychological disorders, no severe stress, no use of herbal or chemical estrogens. Menopause is defined as the time when there are no menstrual periods for 12 previous consecutive months, with no other biological or physiological cause [29]. According to this definition, we included 45-65 years old women without any menstrual period for at least more than 12 consecutive months.

Subjects of the study were recruited by using the multi-stage probability-cluster sampling method. In cluster sampling, researchers divide a population into smaller groups known as clusters. They then randomly select among these clusters to form a sample. Cluster sampling is a method of probability sampling that is used to study large populations, particularly those that are widely geographically dispersed. Therefore, we selected the four geographic regions of Tehran as the first stage of clustering. Then, the health centers were randomly selected as the second stage of clustering. At the last stage, quota sampling was performed to select the subjects of the study. Written informed consent was obtained from every participant.

\section{Measures}

The tools for data collection were; 1) a Sociodemographic questionnaire, 2) the translated version of 
the Menopause Rating Scale (MRS) [30], and 3) Fisher's body image questionnaire [31].

The socio-demographic questionnaire was developed for this study by the researchers and had 10 questions about personal and social characteristics of participants including age, age of menopause, the number of children, educational level of women and their husbands, marital status, occupation of women and their husbands, housing status and adequacy of monthly household income. Adequacy of monthly household income was scored from 1 to 3 for "not adequate", "adequate" and, "adequate and saving" choices (Supplementary file 1).

The Menopause Rating Scale (MRS) is an international, standard scale for rating the severity of menopausal symptoms. It is designed in three sections of somatic (vasomotor), psychological, and urogenital symptoms. The questionnaire consists of 11 questions, the responses to which are scored to the severity of the symptoms with a 5-point Likert scale, including: "none" (0), "mild" (1), "moderate" (2), "severe" (3) and "very severe" (4). A total score equal to or more than 17 , is indicating severe menopausal symptoms [32]. The content and face validity of the MRS questionnaire were confirmed in a previous study [33]. The reliability of the MRS was assessed by the test-retest method and calculating Cronbach's $\alpha$ and ICC of 0.933 and 0.977 , respectively [33].

Fisher's Body Image questionnaire was developed by Fisher [31]. The questionnaire includes 46 items which scores 1 to five (completely unsatisfied $=1$; mostly unsatisfied $=2$; moderate $=3$; mostly satisfied $=4$; completely satisfied $=5$ ) (Ranges 46 to 230). Higher scores show more satisfaction with body image. The questionnaire was validated in Iran $[34,35]$. The stability of the questionnaire was demonstrated by test-retest and Pearson correlation coefficient of more than 0.81. Internal consistency of the questionnaire was also shown by Cronbach's $\alpha 0.93$ and half-splitting correlation coefficient of 0.91 [34]. Nazarpour and Khazai calculated the reliability of this questionnaire by using Cronbach's $\alpha$, Spearman's coefficient, and Guttman half splitting correlation coefficients equal to $0.918,0.861$, and 0.861 , respectively [36].

All the questionnaires were completed using face-toface interviews.

\section{Statistical analyses}

The data were analyzed using the SPSS version 23 (SPSS Inc., Chicago, IL, USA). The continuous variables were checked for normality using the one-sample Kolmogorov-Smirnoff test. The correlation was measured by the Pearson correlation test (for variables with normal distribution), and Spearman's correlation test (for variables with abnormal distribution and ordinal variables), and independent samples $t$-test.
Also, multiple linear regression was used to assess associated factors with body image. The assumption for the multiple linear regression model was that body image MRS and some socio-demographic factors are associated with body image as the outcome and dependent variable. All socio-demographic variables were included in the first block and MRS in the second block.

The socio-demographic factors that entered the model were: age, number of children, duration of menopause, marital status, occupation of women, educational level of women and her husband, their housing status, the adequacy of monthly household income. Because, they have been shown by other studies to be related to body image $[8,11,37]$.

A $P$-value less than 0.05 was considered statistically significant.

\section{Results}

\section{Description of the study sample}

Three hundred women with an average age of $55.11 \pm$ 3.99 (Mean $\pm \mathrm{SD}$ ) years old, with minimum to maximum age 45 to 65 , participated in the study. The duration of menopause was $5.80 \pm 4.42$ months. The mean number of children was $3.34 \pm 1.63$. Ninety-five percent of women were married and $80 \%$ were housewives, $16 \%$ of women were illiterate and $16.3 \%$ had academic education. Fifty-two percent of participants had employed husbands, and remaining women had unemployed- or retired- husbands, and $77.3 \%$ of the subjects had housing ownership status. Socio-demographic characteristics of women are shown in Table 1.

The mean score of body image was $163.07 \pm 11.50$ $(63.63 \pm 11.50 \%)$. The highest and lowest scores were shown for head and face (67.36\%) and lower organs (58.43\%), respectively. Mean scores of body image and its domains are presented in Table 2.

The mean score for MRS was $37.38 \pm 19.04 \%$. The most severe symptoms of MRS were shown in the somatic domain (40.42\%) and the lowest score was shown for the urogenital domain (30.61\%). Severe symptoms (total score $\geq 17$ ) were reported in $49.0 \%$ (147) of women. Mean scores of MRS and its domains are presented in Table 2.

\section{Correlations}

Finding showed that total score and the dimensions of body image have significant negative correlations with total score and all domains of MRS (Table 3).

Results of the study also demonstrated a significant positive correlation between body image with the educational level of women $(P<0.001, \mathrm{r}=0.20)$ and with the husband educational level $(P<0.001, \mathrm{r}=0.26)$ and the adequacy of monthly household income $(P<0.001, \mathrm{r}=$ 0.32 ). There was the same correlation between all 
Table 1 Socio-demographic characteristics of postmenopausal women participated in the study $(N=300)$

\begin{tabular}{|c|c|}
\hline Variables & Mean \pm SD/n (\%) \\
\hline Age (years) & $55.11 \pm 3.99$ \\
\hline Duration of menopause (months) $^{a}$ & $5.80 \pm 4.42$ \\
\hline Number of children & $3.24 \pm 1.63$ \\
\hline \multicolumn{2}{|l|}{ Occupation } \\
\hline Housewife or retired & $262(87.3)$ \\
\hline Employed & $38(12.7)$ \\
\hline \multicolumn{2}{|l|}{ Education } \\
\hline Illiterate & $48(16.0)$ \\
\hline Diploma and under diploma & $203(67.7)$ \\
\hline Higher diploma & $49(16.3)$ \\
\hline \multicolumn{2}{|l|}{ Marital status } \\
\hline Married & $286(95.3)$ \\
\hline Single/ Widow/ Divorced & $14(4.7)$ \\
\hline \multicolumn{2}{|l|}{ Occupation of Husband } \\
\hline Employed & $156(52.0)$ \\
\hline Retired or unemployed & $144(48.0)$ \\
\hline \multicolumn{2}{|l|}{ Education of husband } \\
\hline Illiterate & $31(10.3)$ \\
\hline Diploma and under diploma & $216(72.0)$ \\
\hline Higher diploma & $53(17.7)$ \\
\hline \multicolumn{2}{|l|}{ Housing status } \\
\hline The owner & $232(77.3)$ \\
\hline Non-owner & $68(22.7)$ \\
\hline \multicolumn{2}{|c|}{ The adequacy of monthly household income } \\
\hline Less than adequate & $130(43.3)$ \\
\hline Adequately or with saving & $170(56.7)$ \\
\hline
\end{tabular}

${ }^{a}$ Menopause is defined as the time when there have been no menstrual periods for 12 consecutive months;

dimensions of body image with the same abovementioned characteristics. There was also a significant negative correlation between the numbers of children with a score of lower limbs body image $(P=0.017, \mathrm{r}=-$ 0.14 ((Table 3).

$T$-test demonstrated higher scores for body image of married women comparing with widow/single women $(P=0.036)$, and also for women with housing ownership status compared to women with rental housing status $(P=0.012)$, and for employed women comparing to housewife/retired women $(P=0.007)$.

\section{Regression}

Multiple linear regression analysis showed that the model can show $27.2 \%$ of the variance of total scores for body image. The model also showed that MRS is an associated factor with body image. Otherwise, with increasing one score of MRS, body image decreases by
Table 2 Mean and standard deviation of scores for women's body image and severity menopausal symptoms

\begin{tabular}{lll}
\hline & Score & \\
\hline Body Image & $\begin{array}{l}\text { Mean } \pm \text { SD } \\
(46-230)^{\mathrm{a}}\end{array}$ & $\begin{array}{l}\text { Mean } \pm \text { SD } \\
(0-100)^{\mathrm{a}}\end{array}$ \\
Head \& face (12-60) & $44.33 \pm 5.44$ & $67.36 \pm 11.33$ \\
Upper limbs (10-50) & $34.91 \pm 6.03$ & $62.27 \pm 15.08$ \\
Lower limbs (6-30) & $20.02 \pm 4.27$ & $58.43 \pm 17.80$ \\
Overall & $64.02 \pm 8.48$ & $63.92 \pm 11.78$ \\
Total Body Image & $163.07 \pm 21.17$ & $63.63 \pm 11.50$ \\
MRS & Mean \pm SD & Mean \pm SD \\
& $(0-44)$ & $(0-100)$ \\
Somatic & $6.46 \pm 3.66$ & $40.42 \pm 22.87$ \\
Psychological & $6.31 \pm 4.04$ & $39.42 \pm 25.25$ \\
Urogenital & $3.67 \pm 2.74$ & $30.61 \pm 22.87$ \\
Total score & $16.45 \pm 8.38$ & $37.38 \pm 19.04$ \\
\hline
\end{tabular}

${ }^{\mathrm{a}}$ Total possible range of scores

1.15 units $(P<0.001)$. Also, the adequacy of monthly household income is an associated factor with body image. Otherwise, women with a monthly income had higher scores of body image (Table 4). The interactions between age, number of children, duration of menopausal period, marital status, and women's occupation, educational level of women and her husband, housing status, adequacy of monthly household income were assessed. However, these interaction terms were not included in the final model as they were not statistically significant (Table 4).

\section{Discussion}

The study showed the severity of the menopausal symptom and all of its dimensions have a negative correlation with body image. Also, regression analysis showed the severity of menopausal syndrome is an associated factor with women's body image. By this finding, Włodarczyk \& Dolińska-Zygmunt (2017) showed women with severe vasomotor and psychosomatic symptoms experience low self-confidence and body function [38]. Perimenopausal physical and psychological changes such as gaining weight, insomnia, flushing, and night sweats as well as elderly symptoms like changes in skin and hair, sexual dysfunction, and osteoporosis can change women's attitudes and feelings about their body image [24, 39]. Ginsberg et al. (2016) found a negative correlation between high body mass index with positive body image which means obese postmenopausal women have usually dissatisfied body image [16].

There is evidence to suggest that women's interpretation of their menopausal experiences relates to their attitude towards menopause and body image. For example, women with a negative attitude towards 
Table 3 The correlations between Menopause Rating Scale (MRS) and the socio-demographic factors with women's body image

\begin{tabular}{|c|c|c|c|c|c|}
\hline \multirow[t]{3}{*}{ Variables } & \multicolumn{5}{|c|}{ Body image (four dimensions and total scores). } \\
\hline & Head \& face & Upper limbs & Lower limbs & Overall & Total score \\
\hline & $r$ & $r$ & $r$ & $r$ & $r$ \\
\hline \multicolumn{6}{|c|}{ The severity of menopausal symptoms; Test: Pearson correlation coefficient. } \\
\hline Somatic & $-0.23^{* * *}$ & $-0.35^{* * *}$ & $-0.37^{* * *}$ & $-0.41^{* * *}$ & $-0.40^{* * *}$ \\
\hline Psychological & $-0.33^{* * *}$ & $-0.46^{* * *}$ & $-0.40^{* * *}$ & $-0.47^{* * *}$ & $-0.49^{* * *}$ \\
\hline Urogenital & $-0.30^{* * *}$ & $-0.21^{* * *}$ & $-0.20^{* * *}$ & $-0.27^{* * *}$ & $-0.29^{* * *}$ \\
\hline Total score & $-0.36^{* * *}$ & $-0.45^{* * *}$ & $-0.42^{* * *}$ & $-0.49^{* * *}$ & $-0.51^{* * *}$ \\
\hline \multicolumn{6}{|c|}{ The socio-demographic factors; Test: Spearman's correlation coefficient. } \\
\hline Age & 0.05 & 0.05 & -0.05 & 0.11 & 0.09 \\
\hline Duration of menopause & 0.04 & 0.02 & 0.01 & 0.04 & 0.05 \\
\hline Number of children & -0.02 & -0.03 & $-0.14^{*}$ & 0.04 & -0.03 \\
\hline Education & $0.17^{* *}$ & $0.21^{* * *}$ & $0.23^{* * *}$ & $0.13^{*}$ & $0.20^{* * *}$ \\
\hline Education of Husband & $0.23^{* * *}$ & $0.27^{* * *}$ & $0.26^{* * *}$ & $0.19^{* *}$ & $0.26^{* * *}$ \\
\hline The adequacy of monthly household income & $0.27^{* * *}$ & $0.33^{* * *}$ & $0.29^{* * *}$ & $0.27^{* * *}$ & $0.32^{* * *}$ \\
\hline
\end{tabular}

${ }^{*} P<0.05$. ${ }^{* *} P<0.01$. *** $P<0.001$

menopausal physical changes, like weight gain, think that makes them less sexually desirable [40]. A negative attitude towards menopause is associated with body dissatisfaction, self-objectification, appearance-related aging anxiety, and lower perceived attractiveness during the menopausal transition [40-42]. A study on 350 women in menopause showed that $74.4 \%$ of them feel losing attractiveness after menopause [43]. Therefore, menopausal symptoms are associated with a negative attitude about attractiveness, low self-esteem, and body image [24]. Negative perception about menopausal changes associated with low scores for self-efficacy [44]. Also, changes in the appearance of postmenopausal women are associated with body image concerns which in turn may influence their quality of life [45]. Also, appearancerelated aging concerns and body comparison are two sociocultural factors that moderated the association between menopausal status and disordered body image concerns [46].

We showed a significantly strong negative correlation between urogenital symptoms as a dimension of menopausal symptoms with women's body image and all of its dimensions. It is consistent with the results of other studies showing that women with urogenital symptoms such as urinary incontinence or dyspareunia are unsatisfied with their body image [20, 47]. In this accordance, another study also showed urogenital symptoms especially stress incontinence can have negative impacts on menopausal women's body image [47] as well as on their psychological health $[48,49]$. A comparative study showed women with positive body image had less vaginal moistures and so less orgasmic problem and dyspareunia and then more sexual satisfaction (Zamankhani, 2005).

The results also demonstrated a significant correlation between women's body image with some sociodemographic factors such as the educational level of the women and their husband; their number of children, marital status, income, employment, and housing status in menopause. Although there were no similar studies to show these associations in menopausal women, some studies showing these correlations in other groups of people. For example, a study on 1200 men and women showed a negative correlation between the participants' education with their body dissatisfaction [9]. Another study on 126 women with breast cancer also showed a positive correlation between educational levels with their body image [11]. Also, a study on 1841 women

Table 4 Multiple linear regression analysis for postmenopausal women's body image

\begin{tabular}{|c|c|c|c|c|c|}
\hline \multirow[t]{2}{*}{ Variables } & \multirow[t]{2}{*}{ Beta } & \multirow[t]{2}{*}{$\mathbf{T}$} & \multirow{2}{*}{$\begin{array}{l}P \\
\text { value }\end{array}$} & \multicolumn{2}{|c|}{ 95\% Confidence Interval for B } \\
\hline & & & & Lower & Upper \\
\hline$\overline{M R S}$ & -0.45 & -8.47 & $<0.001$ & -1.41 & -0.88 \\
\hline Adequacy of monthly household income ${ }^{a}$ & 0.15 & 2.83 & 0.005 & 0.85 & 4.75 \\
\hline Adjusted $\mathrm{R}^{2}=0.272 \mathrm{R}^{2}=0.277$ & & & & & \\
\hline
\end{tabular}

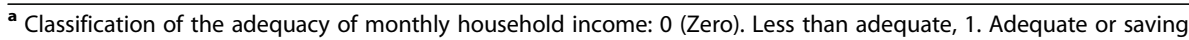


demonstrated a relationship between individual characteristics such as women's education level with women's attitude towards body image and management [37]. It seems high-level educated women manage their menopausal symptoms better than low-level educated women.

There was a positive correlation between monthly household incomes with the women's body image. Also, the regression analysis showed that monthly household income is an associated factor with body image. Similar results were shown in other studies on women affected by breast cancer [11] or among other women [37]. It may be because monthly household incomes are more common among empowered educated, employed, and homeowner women who manage their menopausal symptoms and so have appropriate body image.

The results showed body image of employed women was also significantly higher than unemployed ones. A similar result was shown in women with breast cancer [11]. It was shown that employment impacts women's attitude towards body management [37]. Also, Housing ownership has a positive impact on the body image of women in menopause. A similar finding was also demonstrated in another study among women in all age groups [37]. Therefore, the present study showed the positive relationships between body image with education, employment, income, and housing ownership in menopause. These factors are the indexes of women's empowerment [50] and so the study shows the relationship between women's empowerment with the body image of women during menopause. Therefore, it can be postulated that women's empowerment could be related to women's body image and self-esteem.

This study showed a negative correlation between the numbers of children with lower limbs body image. It seems that the high number of children associate with a high number of vaginal deliveries may lead to a negative lower body image. Besides, the finding of the present study showed that married women have lower scores of body image comparing to single/widow/separated women. It was reported that married women are more unsatisfied with their bodies comparing to single women [9]. So, marital status is an influencing factor on women's attitude towards body management [37].

This was a cross-sectional study that is not able to assess the cause and effect relationship; however, we used regression analysis to find out factors associated with the body image of postmenopausal women as the dependent variable. The regression model demonstrated the two factors including the severity of menopausal symptoms and monthly household income, can be the factors associated with the women's body image. Therefore, further analytical studies are necessary to assess the cause and effect relationship between the severity of menopausal symptoms with the women's body image. This study was the first study showing the relationship between all dimensions of menopausal symptoms with all dimensions of body image in menopausal women. This study could be a base for analytical design studies and interventional studies to improve postmenopausal women's health.

\section{Strengths and limitations}

The strength of the study was that women were not using hormone replacement therapy or phytoestrogenic medicines and so the severity of menopausal symptoms was not affected by these treatments. Also, studies about the effective factors on the body image of menopausal women are rare and this study can be a base for future researches.

A limitation of the study was that the participants were from Tehran, and since sociocultural and economic factors may be effective on postmenopausal women's body image, perhaps further studies are necessary to be conducted in other communities with different conditions. Another limitation of the present study could be that the cross-sectional study did not permit the assessment of cause and effect relationships between severity of menopausal symptoms and also other sociodemographic characteristics with body image. We also recruited the samples from the public primary health care services that rich women are rarely using these services. Some factors were not measured; for example, BMI was not measured as many postmenopausal women are not aware of the meaning of BMI, and also, we could not measure their weight and height in the health centers because of corona-raised limitations. However, the study might have gained by having actual measurements of body size and proportions correlative with subjective image perception.

These factors such as BMI, habits like smoking, and alcohol use dietary and physical activities are suggested to be considered in future studies. It should be also mentioned that in our previous studies that alcohol use and smoking are rare among this group of women. Also, they are sensitive questions in the country, that responses may not be reliable.

\section{Conclusion}

Menopausal symptoms can influence on body image of women in menopause. Postmenopausal women's education, employment, income, and housing ownership are positively correlated with body image. These factors are the indexes of women's empowerment and so women empowerment can improve body image and self-esteem. Although it was a cross-sectional study that was not able to assess the cause and effect relationship; the regression analysis showed that severity of menopausal symptoms and monthly household income, can be associated with women's body image. Therefore, further analytical 
studies are necessary to assess the cause and effect relationship between the severity of menopausal symptoms with the women's body image. This study could be a base for further analytical design studies and future interventional studies to improve postmenopausal women's health. Women empowerment through improving women's education, employment, income, and housing condition should be considered for future policies and programs to promote women's health during menopause.

\section{Abbreviations}

MRS: Menopausal Rating Scale; ICC: Intra-class correlation; SPSS 21: Statistical Package for the Social Sciences (version 21)

\section{Supplementary Information}

The online version contains supplementary material available at https://doi. org/10.1186/s12889-021-11643-6.

\section{Additional file 1.}

\section{Acknowledgments}

Not applicable.

\section{Authors' contributions}

SN developed the project, designed the concept and study, managed the data, carried out data analysis, prepared the first and revised drafts of the manuscript, edited critically the manuscript. MS developed the project, designed the concept and study, managed the data, prepared the first and revised drafts of the manuscript, edited critically the manuscript. HM contributed to the study design and managed data analysis. ZJT carried out data collection and contributed to the preparation of the manuscript. KDA carried out data collection and contributed to the preparation of the manuscript. FR carried out data collection and contributed to the preparation of the manuscript. All authors have read and have approved the manuscript.

\section{Funding}

Not applicable.

\section{Availability of data and materials}

The datasets used and/or analyzed during the current study are available from the corresponding author on reasonable request.

\section{Declarations}

\section{Ethics approval and consent to participate}

The study was approved by the ethics committee of the Shahid Beheshti University of Medical Sciences, with the code "IR.SBMU.PHARMACY.REC.1397.184IRCT20190306042943N2" Written informed consents were, also, obtained from the participants.

\section{Consent for publication}

Not applicable.

\section{Competing interests}

The authors declare that they have no conflict of interest.

\section{Author details}

'Department of Midwifery, Chalous Branch, Islamic Azad University, Chalous, Iran. ${ }^{2}$ Midwifery and Reproductive Health Research Center, Shahid Beheshti University of Medical Sciences, Tehran, Iran. ${ }^{3}$ Department of Midwifery and Reproductive Health, School of Nursing and Midwifery, Shahid Beheshti University of Medical Sciences, Vali-Asr Avenue, Cross of Vali-Asr and Neiaiesh Highway, Opposite to Rajaee Heart Hospital, Tehran 1996835119, Iran.
${ }^{4}$ Department of Biostatistics, School of Paramedicine, Shahid Behesht University of Medical Sciences, Tehran, Iran.

Received: 29 September 2020 Accepted: 20 August 2021

Published online: 30 August 2021

\section{References}

1. Grogan S. Body image: understanding body dissatisfaction in men, women and children. 3rd ed. London: Routledge; 2016. https://doi.org/10.4324/ 9781315681528

2. Swami V, Hadji-Michael M, Furnham A. Personality and individual difference correlates of positive body image. Body Image. 2008;5(3):322-5. https://doi. org/10.1016/j.bodyim.2008.03.007.

3. Moradhaseli M, Manteghi M. Identification process related to development of body image in female adolescent's users of cyberspace in Iran: a qualitative study. J Res Psychol Health. 2017;11(3):62-85.

4. Cash TF, Pruzinsky TE. Body images: development, deviance, and change: Guilford press; 1990

5. Tylka TL, Wood-Barcalow NL. What is and what is not positive body image? Conceptual foundations and construct definition. Body Image. 2015;14:11829. https://doi.org/10.1016/j.bodyim.2015.04.001.

6. Richetin J, Xaiz A, Maravita A, Perugini M. Self-body recognition depends on implicit and explicit self-esteem. Body Image. 2012;9(2):253-60. https://doi. org/10.1016/j.bodyim.2011.11.002

7. Sujoldžić A, De Lucia A. A cross-cultural study of adolescents-BMI, body image and psychological well-being. Coll Antropol. 2007:31(1):123-30.

8. Garrusi B, Baneshi MR. Eating disorders and their associated risk factors among Iranian population-a community based study. Global J Health Sci. 2013:5(1):193-202.

9. Garrusi B, Baneshi MR. Body dissatisfaction among Iranian youth and adults. Cad Saude Publica. 2017;33(9):e00024516. https://doi.org/10.1590/0102-311 X00024516.

10. Fernández-Bustos JG, Infantes-Paniagua Á, Gonzalez-Martí I, ContrerasJordán OR. Body dissatisfaction in adolescents: differences by sex, BMI and type and organisation of physical activity. Int J Environ Res Public Health. 2019;16(17):3109. https://doi.org/10.3390/ijerph16173109.

11. Chang O, Choi E-K, Kim I-R, Nam S-J, Lee JE, Lee SK, et al. Association between socioeconomic status and altered appearance distress, body image, and quality of life among breast cancer patients. Asian Pac J Cancer Prev. 2014;15(20):8607-12. https://doi.org/10.7314/APJCP.2014.15.20.8607.

12. Simbar M, Nazarpour S, Alavi Majd H, Dodel Andarvar K, Jafari Torkamani Z, Alsadat RF. Is body image a predictor of women's depression and anxiety in postmenopausal women? BMC Psychiatry. 2020;20(202):1-8.

13. Izgiç F, Akyüz G, Doğan $O$, Kuğu N. Social phobia among university students and its relation to self-esteem and body image. Can J Psychiatry. 2004;49(9): 630-4. https://doi.org/10.1177/070674370404900910.

14. Kornblau IS, Pearson HC, Breitkopf CR. Demographic, behavioral, and physical correlates of body esteem among low-income female adolescents. J Adolesc Health. 2007;41(6):566-70. https://doi.org/10.1016/j.jadohealth.2 007.06.014.

15. Basaknezhad S, Ghaffari M. Disfigure the body and the relationship between fear of psychological disorders in students. J Behav Sci. 2007:1(2):179-8.

16. Ginsberg RL, Tinker L, Liu J, Gray J, Sangi-Haghpeykar H, Manson JE, et al. Prevalence and correlates of body image dissatisfaction in postmenopausal women. Women Health. 2016;56(1):23-47. https://doi.org/10.1080/0363 0242.2015.1074636.

17. McLean SA, Paxton SJ, Wertheim EH. Mediators of the relationship between media literacy and body dissatisfaction in early adolescent girls: implications for prevention. Body Image. 2013;10(3):282-9. https://doi.org/10.1016/j. bodyim.2013.01.009.

18. Nikniaz Z, Mahdavi R, Amiri S, Ostadrahimi A, Nikniaz L. Factors associated with body image dissatisfaction and distortion among Iranian women. Eat Behav. 2016;22:5-9. https://doi.org/10.1016/j.eatbeh.2016.03.018.

19. Simbar M, Nazarpour S, Mirzababaie M, Emam Hadi MA, Ramezani Tehrani F, Alavi MH. Quality of life and body image of individuals with gender dysphoria. J Sex Marital Ther. 2018;44(6):523-32. https://doi.org/10.1080/ 0092623X.2017.1419392.

20. Pazmany E, Bergeron S, Van Oudenhove L, Verhaeghe J, Enzlin P. Body image and genital self-image in pre-menopausal women with dyspareunia. Arch Sex Behav. 2013:42(6):999-1010. https://doi.org/10.1007/s10508-013-01 $02-4$ 
21. J Jackson KL, Janssen I, Appelhans BM, Kazlauskaite R, Karavolos K, Dugan SA, et al. Body image satisfaction and depression in midlife women: the study of Women's health across the nation (SWAN). Arch Womens Ment Health. 2014;17(3):177-87.

22. Zamankhani Z. The study of sexual function and its relation to body image in postmenopausal women in Shahriar Tehran. Tarbiat Modarres: Iran; 2005.

23. Gümüşay $M$, Erbil N. Alternative methods in the management of menopausal symptoms. Middle Black Sea J Health Sci. 2016;2(2):20-5. https://doi.org/10.19127/mbsjohs.20236.

24. Pearce G, Thøgersen-Ntoumani C, Duda J. Body image during the menopausal transition: a systematic scoping review. Health Psychol Rev. 2014;8(4):473-89. https://doi.org/10.1080/17437199.2013.848408.

25. Santoro N, Epperson CN, Mathews SB. Menopausal symptoms and their management. Endocrinol Metab Clin. 2015;44(3):497-515. https://doi.org/1 0.1016/j.ecl.2015.05.001

26. Abbas J, Aqeel M, Ling J, Ziapour A, Raza MA, Rehna T. Exploring the relationship between intimate partner abuses, resilience, psychological, and physical health problems in Pakistani married couples: a perspective from the collectivistic culture. Sex Relation Ther. 2020:1-30. https://doi.org/10.1 080/14681994.2020.1851673.

27. Dehghani M, Chehrzad M, Jafari Asl M, Soleimani R. Evaluate the relationship between body image satisfaction with the socio-cultural patterns teenage girls in Rasht. J Hamadan Nurs Midwifery. 2013;20(3):26-34.

28. Woertman $L$, Van den Brink F. Body image and female sexual functioning and behavior: a review. J Sex Res. 2012;49(2-3):184-211. https://doi.org/10.1 080/00224499.2012.658586

29. Berek JS. Berek \& Novak's gynecology. 16th ed. Philadelphia: Wolters Kluwer Health/Lippincott Williams \& Wilkins; 2019.

30. Heinemann LA, Potthoff $P$, Schneider HP. International versions of the menopause rating scale (MRS). Health Qual Life Outcomes. 2003;1(1):28. https://doi.org/10.1186/1477-7525-1-28.

31. Fisher S. Body experience in fantasy and behavior. New York: Appleton Century Croftsm, Meredith Corporation; 1970.

32. Heinemann K, Ruebig A, Potthoff P, Schneider HP, Strelow F, Heinemann LA. The menopause rating scale (MRS) scale: a methodological review. Health Qual Life Outcomes. 2004;2(1):45. https://doi.org/10.1186/1477-7525-2-45.

33. Nazarpour S, Simbar M, Tehrani FR, Majd HA. The relationship between menopausal symptoms and sexual function. Women Health. 2018:58(10): 1112-23. https://doi.org/10.1080/03630242.2017.1414100.

34. Asgari P, Pasha GR, Aminiyan M. Relationship between emotion regulation, mental stresses and body image with eating disorders of women. Andisheh Va Raftar (Applied Psychology). 2009:4(13):65-78.

35. Fisher body image test, 1st edn. Tehran: Testing company of Yar Puya; 2010

36. Nazarpour S, Khazai K. Correlation between body image and coping styles with severity of primary dysmenorrhea. J Fundamentals Mental Health. 2012;14(56):344-55.

37. Baratlou F, Khodi M. The effect of individual factors on women's attitudes toward body in Tehran. J Cultural Manag. 2015;9(28):113-23.

38. Włodarczyk M, Dolińska-Zygmunt G. Role of the body self and self-esteem in experiencing the intensity of menopausal symptoms. Psychiatr Pol. 2017; 51(5):909-21. https://doi.org/10.12740/PP/68136.

39. Erbil N. Attitudes towards menopause and depression, body image of women during menopause. Alexandria J Med. 2018;54(3):241-6. https://doi. org/10.1016/j.ajme.2017.05.012.

40. McKinley NM, Lyon LA. Menopausal attitudes, objectified body consciousness, aging anxiety, and body esteem: European American women's body experiences in midlife. Body Image. 2008:5(4):375-80. https://doi.org/10.1016/j.bodyim.2008.07.001.

41. Koch PB, Mansfield PK, Thurau D, Carey M. "Feeling frumpy": the relationships between body image and sexual response changes in midlife women. J Sex Res. 2005;42(3):215-23. https://doi.org/10.1080/002244 90509552276.

42. Rubenstein HR, Foster JLH. The relationship between attitudes to menopause and self-objectification, body shame and body surveillance: University of Cambridge; 2013.

43. Hakimi S, Nazarpour S, Ramezani Tehrani F, Simbar M, Zaiery F. Women's experiences about menopause and related factors. Iran J Endocrinol Metab. 2017;19(3):185-93.

44. Ayers B, Forshaw M, Hunter MS. The impact of attitudes towards the menopause on women's symptom experience: a systematic review. Maturitas. 2010;65(1):28-36. https://doi.org/10.1016/j.maturitas.2009.10.016.
45. Rubinstein HR, Foster JL. 'I don't know whether it is to do with age or to do with hormones and whether it is do with a stage in your life': making sense of menopause and the body. J Health Psychol. 2013;18(2):292-307. https:// doi.org/10.1177/1359105312454040.

46. Thompson KA, Bardone-Cone AM. Evaluating attitudes about aging and body comparison as moderators of the relationship between menopausal status and disordered eating and body image concerns among middleaged women. Maturitas. 2019;124:25-31. https://doi.org/10.1016/j.maturitas.2 019.03.014.

47. Hunter MM, Nakagawa S, Van Den Eeden SK, Kuppermann M, Huang AJ. Predictors of impact of vaginal symptoms in postmenopausal women. Menopause (New York, NY). 2016;23(1):40-6.

48. Avis N, Zhao X, Johannes C, Ory M, Brockwell S, Greendale G. Correlates of sexual function among multi-ethnic middle-aged women. Menopause. 2018:25(11):1244-55. https://doi.org/10.1097/GME.0000000000001226.

49. Beyene Y, Gilliss C, Lee K. "I take the good with the bad, and I moisturize": defying middle age in the new millennium. Menopause. 2007;14(4):734-41. https://doi.org/10.1097/gme.0b013e31802f91de.

50. Kiani Z, Simbar M, Dolatian M, Zayeri F. Correlation between social determinants of health and women's empowerment in reproductive decision-making among Iranian women. Global J Health Sci. 2016;8(9): 54913. https://doi.org/10.5539/gihs.v8n9p312.

\section{Publisher's Note}

Springer Nature remains neutral with regard to jurisdictional claims in published maps and institutional affiliations.
Ready to submit your research? Choose BMC and benefit from:

- fast, convenient online submission

- thorough peer review by experienced researchers in your field

- rapid publication on acceptance

- support for research data, including large and complex data types

- gold Open Access which fosters wider collaboration and increased citations

- maximum visibility for your research: over $100 \mathrm{M}$ website views per year

At $\mathrm{BMC}$, research is always in progress.

Learn more biomedcentral.com/submissions 